\title{
Impact of postoperative pleurodesis on pulmonary function after lung segmentectomy
}

Atsushi Kagimoto, MD, Yasuhiro Tsutani, MD, PhD, Yuya Hirai, MD, Yoshinori Handa, MD, PhD, Takahiro Mimae, MD, PhD, Yoshihiro Miyata, MD, PhD, and Morihito Okada, MD, PhD

\section{ABSTRACT}

Objective: Pleurodesis is among several treatment strategies for postoperative alveolo-pleural fistula (APF) after lung resection. Accordingly, the present study aimed to determine the influence of pleurodesis on postoperative pulmonary function.

Methods: Patients who underwent anatomical segmentectomy between January 2009 and March 2020 and pulmonary function tests 6 and 12 months after initial surgery were included in this study. Differences in pulmonary function decline between patients who did and did not undergo pleurodesis were compared.

Results: Among the 319 patients included, 39 (12.2\%) underwent pleurodesis. Among patients who did not receive pleurodesis, there were no difference in decline of vital capacity at 6 months $(-13.7 \% \pm 1.1 \%$ vs $-11.2 \% \pm 0.7 \%$; $P=.063)$ and 12 months $(-10.7 \% \pm 1.3 \%$ vs $-9.5 \% \pm 0.7 \% ; P=.391)$ after surgery between patients who had APF on postoperative day 2 and those who did not. Patients who received pleurodesis had a significantly larger decline in vital capacity at 6 months $(-19.4 \% \pm 2.4 \%$ vs $-13.7 \% \pm 1.1 \% ; P=.015)$ and 12 months $(-16.2 \% \pm 1.6 \%$ vs $-10.7 \% \pm 1.3 \% ; P=.010)$ after surgery compared with those who had APF on postoperative day 2 and did not receive pleurodesis. There were no significant differences in decline of forced expiratory volume in 1 second.

Conclusions: Pleurodesis negatively influenced postoperative vital capacity after lung segmentectomy. Although the clinical influence of this is unknown, careful consideration is needed before performing pleurodesis given its potential influence on postoperative pulmonary function. (JTCVS Open 2021;5:110-8)

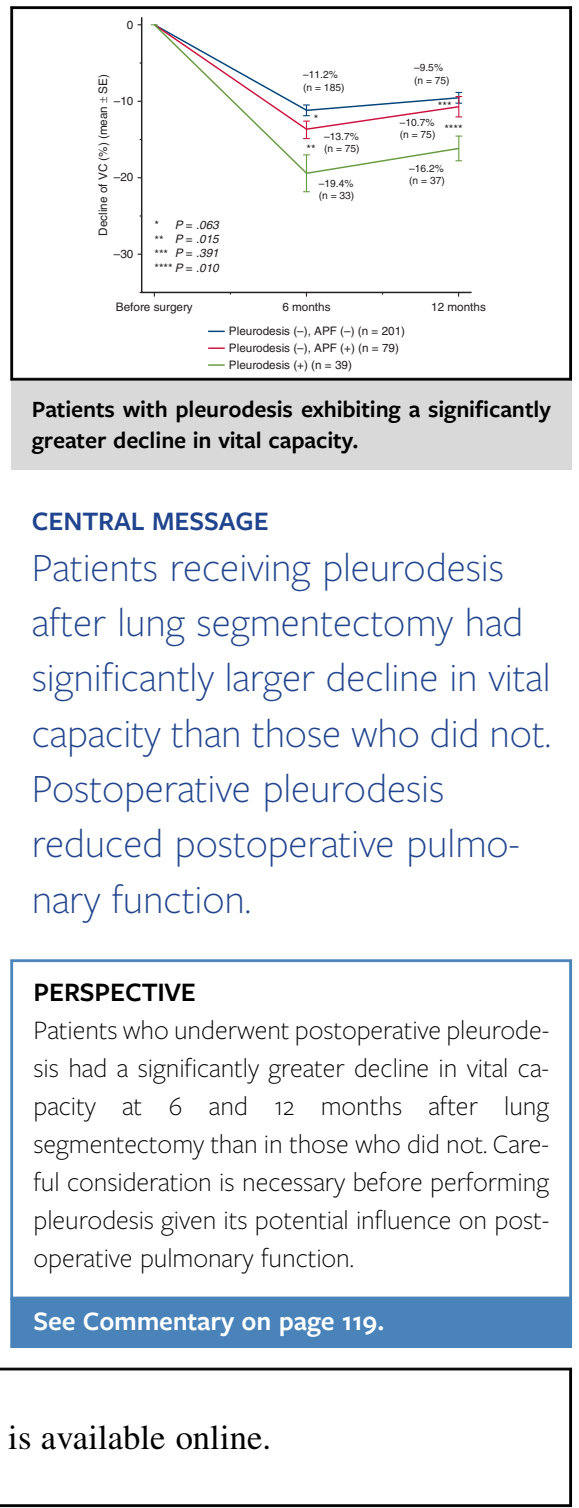

Video clip is available online.

Given the recent improvements in imaging modalities, such as high-resolution computed tomography (CT) or 18-fluorodeoxyglucose positron emission tomography (18-FDG-PET)/CT, early-stage lung cancer has been more frequently detected. ${ }^{1}$ Although the standard procedure for treating non-small-cell lung cancer is lobectomy according to the results of a randomized trial, ${ }^{2}$ many studies since the 2000s have reported that segmentectomy can be safe and provide oncologically acceptable results for small-size
From the Department of Surgical Oncology, Hiroshima University Hospital, Hiroshima, Japan.

Received for publication Dec 12, 2020; accepted for publication Dec 14, 2020 available ahead of print Jan 11, 2021

Address for reprints: Morihito Okada, MD, PhD, Department of Surgical Oncology, Hiroshima University, 1-2-3, Kasumi, Minami-ku, Hiroshima, Japan 734-8551 (E-mail: morihito@hiroshima-u.ac.jp).

2666-2736

Copyright $@ 2020$ The Authors. Published by Elsevier Inc. on behalf of The American Association for Thoracic Surgery. This is an open access article under the CC BY-NCND license (http://creativecommons.org/licenses/by-nc-nd/4.0/).

https://doi.org/10.1016/j.xjon.2020.12.005 


$$
\begin{aligned}
& \text { Abbreviations and Acronyms } \\
& \text { APF }=\text { alveolo-pleural fistula } \\
& \text { CT }=\text { computed tomography } \\
& \text { FEV1 }=\text { forced expiratory volume in } 1 \text { second } \\
& \text { IP }=\text { interstitial pneumonia } \\
& \text { POD }=\text { postoperative day } \\
& \text { VC }=\text { vital capacity }
\end{aligned}
$$

non-small-cell lung cancer. ${ }^{3-5}$ Therefore, segmentectomy will be performed more frequently in the future.

Although a large randomized controlled trial showed no difference in mortality and incidence of severe complication between lobectomy and segmentectomy, patients undergoing segmentectomy more frequently experienced postoperative alveolo-pleural fistula (APF) and chest tube reinsertions than those undergoing lobectomy, ${ }^{6}$ suggesting that opportunity for addressing APF may increase after pulmonary surgery.

Pleurodesis is among several treatment strategies for patients with prolonged APF. Several reports have demonstrated the usefulness of pleurodesis, generally performed in clinical practice, in resolving prolonged APF. ${ }^{7,8}$ However, no studies have investigated the influence of pleurodesis on postoperative pulmonary function. Considering that the advantage of segmentectomy over lobectomy is the preservation of pulmonary function after surgery, ${ }^{9}$ understanding the influence of pleurodesis after segmentectomy on postoperative pulmonary function is important. Therefore, the
HIROSHIMA UNIVERSITY

\section{Impact of postoperative pleurodesis on pulmonary function after lung segmentectomy}

\author{
Hiroshima University, Department of Surgical Oncology \\ Atsushi Kagimoto, Yasuhiro Tsutani, Yuya Hirai, Yoshinori Handa \\ Takahiro Mimae, Yoshihiro Miyata, Morihito Okada
}

VIDEO 1. Digest of our study. Patients who underwent postoperative pleurodesis had a significantly greater decline in vital capacity at 6 and 12 months after lung segmentectomy than those who did not undergo pleurodesis. Although there were no significant differences, it appears that the decline in the vital capacity was slightly greater in patients who underwent pleurodesis and used talc. Careful consideration is necessary before pleurodesis is performed, considering its influence on the postoperative pulmonary function. Video available at: https://www.jtcvs.org/article/ S2666-2736(20)30199-6/fulltext.

present study aimed to investigate whether there were differences in pulmonary function 6 and 12 months after lung segmentectomy and compared them between patients who did and did not receive pleurodesis (Video 1).

\section{METHODS \\ Patients}

The Institutional Review Board of Hiroshima University Hospital approved this retrospective study and waived the requirement for informed consent from individual patients. Patients who underwent anatomical segmentectomy at our institute between January 2009 and March 2020 and

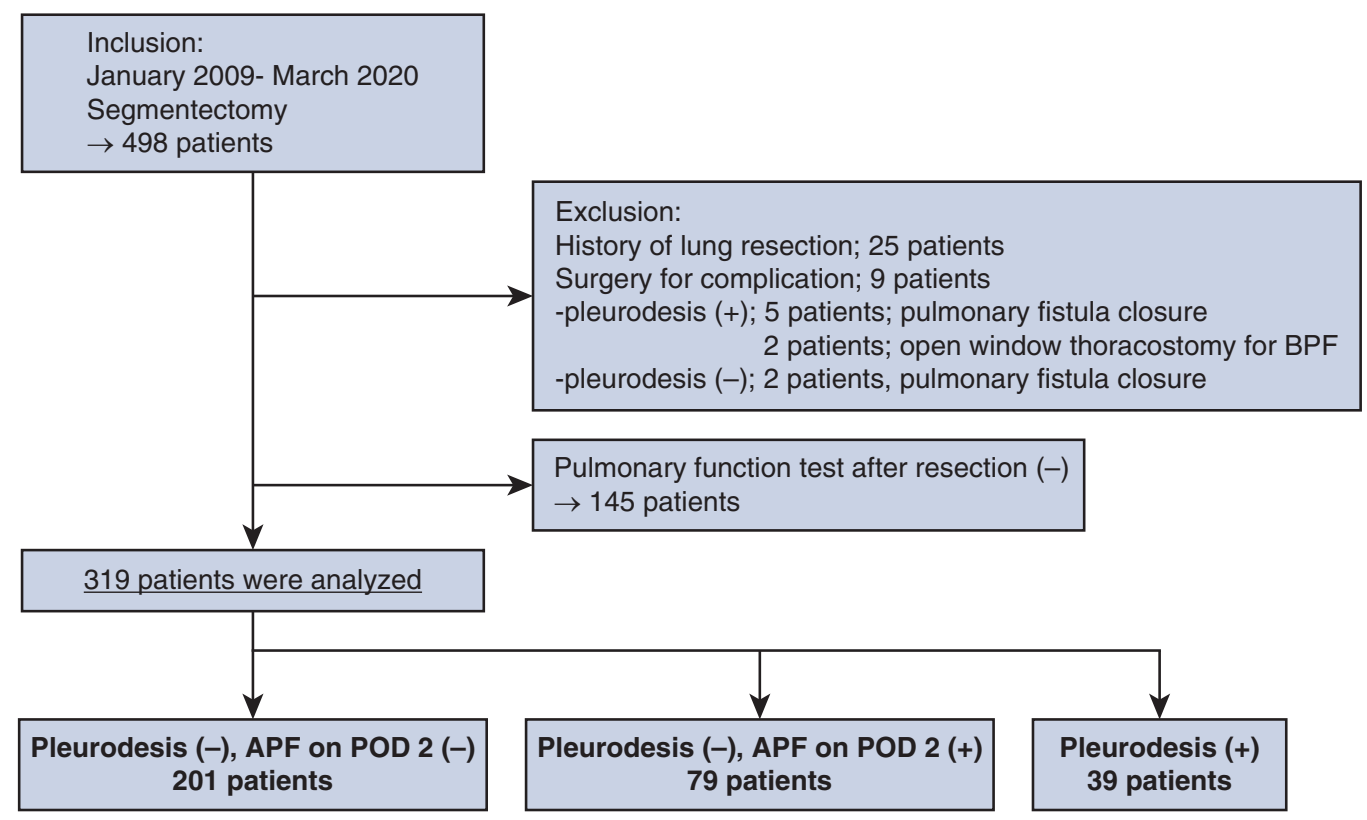

FIGURE 1. Flow chart of patient inclusion. This study included patients who underwent segmentectomy from January 2009 to March 2020 . Patients with a history of lung resection or those who underwent surgery for complications were excluded. In total, 319 patients were enrolled. Patients were divided into the following 3 groups: those without alveolo-pleural fistula $(A P F)$, those with APF who did not undergo pleurodesis, and those who underwent pleurodesis; the changes in the pulmonary function were compared among the groups. $B P F$, Broncho-pleural fistula; $P O D$, postoperative day. 
pulmonary function testing 6 and 12 months after the initial surgery were included in this study. Patients who underwent reoperation for postoperative complication, had a history of previous lung resection, and did not undergo pulmonary function testing after surgery were excluded. A patient selection flow chart is presented in Figure 1.

\section{Preoperative and Postoperative Examination}

Preoperative evaluations, including chest $\mathrm{CT}$ and pulmonary function tests, were performed to determine treatment strategies. In cases of primary lung cancer, whole-body FDG-PET/CT and brain magnetic resonance imaging were performed to determine the clinical stage and indications for surgery. Preoperative pulmonary function tests measured vital capacity (VC), forced expiratory volume in 1 second (FEV1), and diffusing capacity for carbon monoxide. Postoperative follow-up procedures, including physical examination, chest CT scans, and pulmonary function test, were performed every 6 months for 1 year. Patients with primary lung cancer underwent physical examination and chest CT scans for 5 years. Patient characteristics, presence or absence of pleurodesis, and postoperative pulmonary function were retrospectively reviewed from patient records.

\section{Surgical Procedures and Postoperative Management}

Almost all included patients (298 out of 319 [93.4\%]) underwent hybrid video-assisted thoracic surgery, ${ }^{10}$ with $21(6.6 \%)$ undergoing robotassisted thoracic surgery. ${ }^{11}$ The pulmonary artery and vein for the target segment were identified and cut using autosutures or energy devices. The central intersegmental plane was marked along the intersegmental vein. The remaining intersegmental plane was identified from the inflate- deflate line created by the jet ventilation from the target bronchus. The intersegmental plane was cut through electrocautery and enforced using fibulin glue (Beriplast P Combi-Set Tissue adhesion, CSL Behring, Tokyo, Japan) and polyglycolic acid sheets (Neoveil sheet, Gunze Medical Japan, Osaka, Japan). A chest tube (19 Fr Blake Drain, Johnson \& Johnson, New Brunswick, NJ) was placed in the apex of the thoracic cavity before the chest was closed. Segmentectomy was further categorized into simple or complex according to the number of intersegmental planes. ${ }^{12}$ When no APF was observed after surgery, chest tubes were removed on postoperative day (POD) 1 or 2, regardless of the fluid volume. Pleurodesis was considered a treatment option when APF persisted. Sterilized controlled talc (Unitalc; Nobelpharma, Tokyo, Japan), a killed streptococcal preparation of OK-432 (Picibanil; Chugai Pharmaceutical, Tokyo, Japan), and minocycline were mainly used for pleurodesis in our cohort. At our institution, we could not reach a consensus regarding the protocol for pleurodesis because the surgeons' preferences were different. Some surgeons performed pleurodesis early in anticipation of early alveolar pleural fistula closure, whereas others were reluctant to perform pleurodesis owing to the associated complications and the influence on pulmonary function. Therefore, pleurodesis administration, timing, or materials used were left to the discretion of the attending surgeon of each patient without strict rules.

\section{Statistical Analysis}

Patient characteristics and decline in pulmonary function were analyzed in all included patients. To minimize the influence of existing postoperative APF on pulmonary function, the included patients were divided into the following 3 groups: patients without APF, those with APF on POD 2 who did not

\section{TABLE 1. Patient characteristics}

\begin{tabular}{|c|c|c|c|c|}
\hline Variable & No pleurodesis, no APF $(n=201)$ & No pleurodesis, APF on POD $2(n=79)$ & Pleurodesis $(\mathbf{n}=39)$ & $P$ value \\
\hline Age (y) (IQR) & $68(61-75)$ & $71(64-75)$ & 75 (69-79) & .713 \\
\hline Male sex & $98(48.8)$ & $58(67.1)$ & $23(59.0)$ & .389 \\
\hline $\begin{array}{l}\text { Disease } \\
\text { Primary lung cancer } \\
\text { Metastatic lung cancer } \\
\text { Others }\end{array}$ & $\begin{array}{c}179(89.1) \\
11(5.5) \\
11(5.5)\end{array}$ & $\begin{array}{c}73(92.4) \\
3(3.8) \\
3(3.8)\end{array}$ & $\begin{array}{c}33(84.6) \\
5(12.8) \\
1(2.6)\end{array}$ & .202 \\
\hline $\begin{array}{l}\text { Pulmonary function } \\
\qquad \text { VC (L) (IQR) } \\
\text { FEV1 (L) (IQR) } \\
\text { DLCO (\%) (IQR) }\end{array}$ & $\begin{array}{l}2.97(2.42-3.67) \\
2.16(1.78-2.57) \\
80.8(67.9-89.8)\end{array}$ & $\begin{array}{l}3.08(2.57-3.65) \\
2.30(1.73-2.70) \\
75.8(62.1-89.3)\end{array}$ & $\begin{array}{l}2.92(2.73-3.83) \\
2.22(1.88-2.76) \\
79.5(67.0-95.6)\end{array}$ & $\begin{array}{l}.843 \\
.598 \\
.340\end{array}$ \\
\hline $\begin{array}{l}\text { Pulmonary comorbidities } \\
\text { Interstitial pneumonia } \\
\text { Emphysema }\end{array}$ & $\begin{array}{c}15(7.5) \\
36(17.9)\end{array}$ & $\begin{array}{l}11(13.9) \\
30(38.0)\end{array}$ & $\begin{array}{c}3(7.7) \\
7(18.0)\end{array}$ & $\begin{array}{l}.309 \\
.023\end{array}$ \\
\hline $\begin{array}{l}\text { Approach } \\
\text { hVATS } \\
\text { RATS }\end{array}$ & $\begin{array}{c}190(94.5) \\
11(5.5)\end{array}$ & $\begin{array}{c}77(97.5) \\
2(2.5)\end{array}$ & $\begin{array}{c}35(89.7) \\
4(10.3)\end{array}$ & .084 \\
\hline $\begin{array}{l}\text { Resected segments } \\
\quad 1 \\
1.5 \\
2 \\
3 \\
4\end{array}$ & $\begin{array}{c}136(67.7) \\
5(2.5) \\
48(23.9) \\
11(5.5) \\
1(0.5) \\
138\end{array}$ & $\begin{aligned} 36 & (45.6) \\
7 & (8.9) \\
31 & (39.2) \\
3 & (3.8) \\
2 & (2.5)\end{aligned}$ & $\begin{aligned} 17 & (43.6) \\
2 & (5.1) \\
17 & (43.6) \\
1 & (2.6) \\
& 2(5.1)\end{aligned}$ & .867 \\
\hline $\begin{array}{l}\text { Procedure } \\
\text { Simple segmentectomy } \\
\text { Complex segmentectomy }\end{array}$ & $\begin{array}{c}81(40.3) \\
120(59.7)\end{array}$ & $\begin{array}{l}33(41.8) \\
46(58.2)\end{array}$ & $\begin{array}{l}17(43.6) \\
22(56.4)\end{array}$ & .851 \\
\hline
\end{tabular}

Values are presented as median (interquartile range) or $\mathrm{n}(\%)$. $A P F$, Alveolo-pleural fistula; $P O D$, postoperative day; $V C$, vital capacity; $F E V I$, forced expiratory volume in one second; DLCO, diffusing capacity for carbon monoxide; $h V A T S$, hybrid video assisted thoracic surgery; RATS, robot assisted thoracic surgery; IQR, interquartile range. *Differences between no pleurodesis APF on POD $2(\mathrm{n}=79)$ and pleurodesis $(\mathrm{n}=39)$. 
undergo pleurodesis, and those who underwent pleurodesis. POD 2 was set as a cutoff line because we usually remove the chest tube if there was no APF and there were patients who underwent pleurodesis on POD 2. Among patients who underwent pleurodesis, pulmonary function was compared between patients who did and did not use talc. Continuous variables are presented as median and interquartile range, categorical variables are presented as $\mathrm{n}(\%)$, and postoperative changes in pulmonary function are presented as mean \pm standard error. Categorical variables were compared using the $\chi^{2}$ test, whereas continuous variables were analyzed using Student $t$ tests. Resected segments were calculated as the total number of resected segments, with subsegments being considered half a segment. All statistical analyses were conducted using JMP software version 14. (SAS Institute, Cary, NC).

\section{RESULTS}

A total of 319 patients were included in this study. Among these, 201 (63.0\%) had no APF, 79 (24.8\%) had APF on POD 2 and did not undergo pleurodesis, and 39 $(12.2 \%)$ underwent pleurodesis (Figure 1). The characteristics of the included patients are summarized in Table 1 . The causes of pleurodesis were APF (38 patients [97.4\%]) and chylothorax (1 patient [2.6\%]). No significant differences were observed in VC $(P=.843), \operatorname{FEV} 1(P=.598)$, and diffusing capacity for carbon monoxide $(P=.340)$ between

TABLE 2. Surgical procedures of all included patients

\begin{tabular}{|c|c|c|c|c|}
\hline Procedure & No pleurodesis, no APF $(n=201)$ & No pleurodesis, APF $(n=79)$ & Pleurodesis $(\mathbf{n}=39)$ & $P$ value* \\
\hline Procedure & & & & .046 \\
\hline \multicolumn{5}{|l|}{ Left } \\
\hline $\mathrm{S} 1+2$ & $21(10.4)$ & $7(8.9)$ & $6(15.4)$ & \\
\hline $\mathrm{S} 1+2 \mathrm{ab}$ & $0(0)$ & $1(1.2)$ & $0(0)$ & \\
\hline $\mathrm{S} 1+2+3$ & $21(10.4)$ & $20(25.3)$ & $11(28.2)$ & \\
\hline $\mathrm{S} 1+2+6$ & $0(0)$ & $1(1.2)$ & $0(0)$ & \\
\hline S3 & $8(4.0)$ & $4(5.1)$ & $1(2.6)$ & \\
\hline $\mathrm{S} 3+4+5$ & $1(0.5)$ & $1(1.2)$ & $0(0)$ & \\
\hline$S 4+5$ & $6(3.0)$ & $0(0)$ & $2(5.1)$ & \\
\hline S6 & $26(12.9)$ & $6(7.6)$ & $0(0)$ & \\
\hline $\mathrm{S} 6+8$ & $0(0)$ & $1(1.2)$ & $0(0)$ & \\
\hline$S 6+10$ & $0(0)$ & $1(1.2)$ & $0(0)$ & \\
\hline S8 & $2(1.0)$ & $0(0)$ & $1(2.6)$ & \\
\hline$S 8+9$ & $3(1.5)$ & $0(0)$ & $2(5.1)$ & \\
\hline $\mathrm{S} 8+9+10$ & $6(3.0)$ & $2(2.5)$ & $0(0)$ & \\
\hline $\mathrm{S} 9+10$ & $2(1.0)$ & $1(1.2)$ & $0(0)$ & \\
\hline $\mathrm{S} 10$ & $3(1.5)$ & $0(0)$ & $0(0)$ & \\
\hline \multicolumn{5}{|l|}{ Right } \\
\hline $\mathrm{S} 1$ & $11(5.5)$ & $7(8.9)$ & $1(2.6)$ & \\
\hline $\mathrm{S} 1 \mathrm{a}+2$ & $1(0.5)$ & $5(6.3)$ & $1(2.6)$ & \\
\hline $\mathrm{S} 1+2$ & $5(2.5)$ & $0(0)$ & $0(0)$ & \\
\hline $\mathrm{S} 1+2+6$ & $0(0)$ & $0(0)$ & $1(2.6)$ & \\
\hline $\mathrm{S} 1+3$ & $0(0)$ & $1(1.2)$ & $1(2.6)$ & \\
\hline $\mathrm{S} 1 \mathrm{~b}+3$ & $2(1.0)$ & $0(0)$ & $0(0)$ & \\
\hline $\mathrm{S} 2$ & $13(6.5)$ & $4(5.1)$ & $2(5.1)$ & \\
\hline $\mathrm{S} 2+3 \mathrm{a}$ & $1(0.5)$ & $2(2.5)$ & $0(0)$ & \\
\hline $\mathrm{S} 2 \mathrm{~b}+3 \mathrm{a}$ & $0(0)$ & $0(0)$ & $1(2.6)$ & \\
\hline $\mathrm{S} 2+\mathrm{S} 6$ & $0(0)$ & $1(1.2)$ & $0(0)$ & \\
\hline S3 & $10(5.0)$ & $1(1.2)$ & $3(7.7)$ & \\
\hline S6 & $27(13.4)$ & $4(5.1)$ & $2(5.1)$ & \\
\hline$S 6+7$ & $1(0.5)$ & $0(0)$ & $0(0)$ & \\
\hline $\mathrm{S} 6+8 \mathrm{a}$ & $1(0.5)$ & $0(0)$ & $1(2.6)$ & \\
\hline $\mathrm{S} 6+9+10$ & $2(1.0)$ & $0(0)$ & $0(0)$ & \\
\hline $\mathrm{S} 6+10 \mathrm{a}$ & $0(0)$ & $1(1.2)$ & $0(0)$ & \\
\hline S7 & $3(1.5)$ & $0(0)$ & $0(0)$ & \\
\hline $\mathrm{S} 7+8+9$ & $1(0.5)$ & $0(0)$ & $0(0)$ & \\
\hline $\mathrm{S} 7+8+9+10$ & $1(0.5)$ & $2(2.5)$ & $2(5.1)$ & \\
\hline S8 & $5(2.5)$ & $2(2.5)$ & $0(0)$ & \\
\hline $\mathrm{S} 8+9$ & $4(2.0)$ & $1(1.2)$ & $1(2.6)$ & \\
\hline $\mathrm{S} 8+9+10$ & $1(0.5)$ & $0(0)$ & $0(0)$ & \\
\hline S9 & $3(1.5)$ & $0(0)$ & $0(0)$ & \\
\hline$S 9+10$ & $6(3.0)$ & $3(3.8)$ & $0(0)$ & \\
\hline $\mathrm{S} 10$ & $4(2.0)$ & $0(0)$ & $0(0)$ & \\
\hline
\end{tabular}

Values are presented as $\mathrm{n}(\%)$. APF, Alveolo-pleural fistula. *Differences between no pleurodesis APF on postoperative day $2(\mathrm{n}=79)$ and pleurodesis $(\mathrm{n}=39)$. 

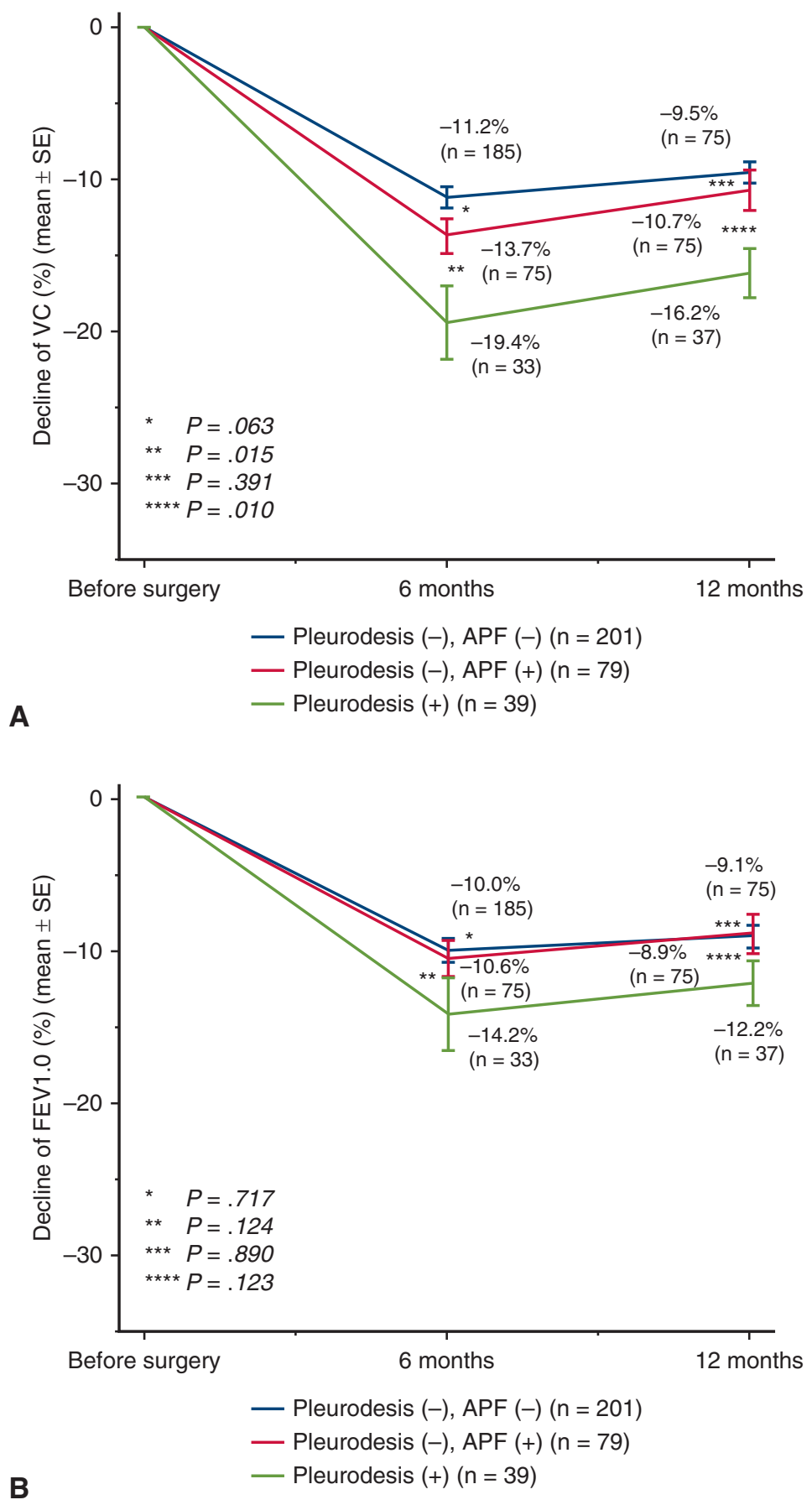

FIGURE 2. A, Changes in vital capacity $(V C)$ from preoperative examination. Among patients who did not undergo pleurodesis, there were no differences in the decline of VC at 6 months $(-13.7 \% \pm 1.1 \%$ vs $-11.2 \% \pm 0.7 \% ; P=.063)$ and 12 months $(-10.7 \% \pm 1.3 \%$ vs $-9.5 \% \pm 0.7 \% ; P=.391)$ postoperatively between patients who did and did not have alveolo-pleural fistula (APF) on postoperative (POD) 2. Patients who underwent pleurodesis had a significantly greater decline in VC at 6 months $(-19.4 \% \pm 2.4 \%$ vs $-13.7 \% \pm 1.1 \% ; P=.015)$ and 12 months postoperatively $(-16.2 \% \pm 1.6 \%$ vs $-10.7 \% \pm 1.3 \% ; P=.010)$ than those who had APF and did not undergo pleurodesis. B, Changes in forced expiratory volume in 1 second (FEV1.0) from preoperative examination. Among patients who did not undergo pleurodesis, there was no difference in the decline of FEV1.0 at 6 months $(-10.0 \% \pm 0.8 \%$ vs $-10.6 \% \pm 1.2 \% ; P=.717)$ and 12 months $(-9.1 \% \pm 0.8 \%$ vs $-8.9 \% \pm 1.3 \% ; P=.890)$ postoperatively between patients who did and did not have had APF on POD 2. Further, there were no significant differences in decline of FEV1.0 at 6 months $(-14.2 \% \pm 2.3 \%$ vs $-10.6 \% \pm 1.2 \% ; P=.124)$ and 12 months $(-12.2 \% \pm 1.5 \%$ vs $-8.9 \% \pm 1.3 \% ; P=.123)$ postoperatively between patients who had APF and did not undergo pleurodesis and those who underwent pleurodesis. $S E$, Standard error. 
the patients who had APF on POD 2 and did not undergo pleurodesis and those who underwent pleurodesis. There was no difference in the prevalence of interstitial pneumonia (IP) $(P=.309)$. Emphysema was frequently observed in patients who had APF on POD 2 but did not undergo pleurodesis $(P=.023)$. The procedures were different for the groups (Table 2) $(P=.046)$; however, there was no difference in the number of resected segments between patients who had APF on POD 2 and did not undergo pleurodesis (average, 1.59) and those who underwent pleurodesis (average, 1.67; $P=.572$ ) (Table 1). The detailed surgical method is described in Table 2.

Changes in the pulmonary function at 6 months and 12 months postoperatively are presented in Figure 2. Among patients who did not undergo pleurodesis, there was no difference in the decline in $\mathrm{VC}$ at 6 months $(-13.7 \% \pm 1.1 \%$ vs $-11.2 \% \pm 0.7 \% ; P=.063)$ and 12 months $(-10.7 \% \pm 1.3 \%$ vs $-9.5 \% \pm 0.7 \%$; $P=.391)$ postoperatively between patients who had APF on POD 2 and those who did not have APF on POD 2. Patients who underwent pleurodesis had a significantly greater decline in $\mathrm{VC}$ at 6 months $(-19.4 \% \pm 2.4 \%$ vs $-13.7 \% \pm 1.1 \% ; \quad P=.015)$ and 12 months $(-16.2 \% \pm 1.6 \%$ vs $-10.7 \% \pm 1.3 \% ; P=.010)$ postoperatively than those who had APF on POD 2 and did not undergo pleurodesis (Figure 2, A). Among patients who did not undergo pleurodesis, there were no differences in the decline of FEV1 at 6 months $(-10.0 \% \pm 0.8 \%$ vs $-10.6 \% \pm 1.2 \% ; P=.717)$ and 12 months $(-9.1 \% \pm 0.8 \%$ vs $-8.9 \% \pm 1.3 \% ; P=.890)$ postoperatively between patients who had APF and those who did not have APF. Further, there was no significant difference in the decline in FEV1 at 6 months $(-14.2 \% \pm 2.3 \%$ vs $-10.6 \% \pm 1.2 \% ; P=.124)$ and at 12 months $(-12.2 \% \pm 1.5 \%$ vs $-8.9 \% \pm 1.3 \% ; P=.123)$ postoperatively between patients who had APF on POD 2 but did not undergo pleurodesis and those who underwent pleurodesis (Figure 2, B). A comparison of patients who only had 1 segment removed and those who underwent pleurodesis showed a significantly greater decline in $\mathrm{VC}$ at 6 months $(-22.3 \%$ vs $-10.9 \% ; P=.003)$ postoperatively than those who had APF on POD 2 and did not undergo pleurodesis. The difference in $\mathrm{VC}$ at 12 months postoperatively surgery was not significant $(-14.9 \%$ vs $-8.6 \% ; P=.062)$. Patients who underwent pleurodesis had a significantly greater decline in FEV1 at 6 months $(-16.3 \%$ vs $-7.6 \%$; $P=.045)$ postoperatively than those who had APF on POD 2 and did not undergo pleurodesis. There was no difference in the decline in FEV1 at 12 months $(-9.4 \%$ vs $-6.3 \% ; P=.395)$ postoperatively compared with those who had APF on POD 2 and did not undergo pleurodesis.

The detailed characteristics of patients who underwent pleurodesis are presented in Table 3. Pleurodesis was performed on a median of 4 days following surgery. The
TABLE 3. Detailed characteristics of patients with pleurodesis $(\mathbf{n}=39)$

\begin{tabular}{|cc}
\hline \multicolumn{1}{c}{ Variable } & Result \\
\hline Frequency of pleurodesis performed & 31 \\
1 & 4 \\
2 & 2 \\
3 & 2 \\
\hline & $4(2-8)$ \\
Days from drainage to pleurodesis & \\
Material used for pleurodesis & 33 \\
Talc & 16 \\
OK-432 & 2 \\
$50 \%$ Glucose solution & 1 \\
Minocycline & 1 \\
$\quad$ Autologous blood patch & $3(1-12)$ \\
\hline Days from pleurodesis to chest tube removal & \\
\hline Values are presented as $n$ or $n$ (range). &
\end{tabular}

majority of patients $(31$ [79.5\%]) underwent pleurodesis only once, but $8(20.5 \%)$ underwent multiple pleurodesis procedures. Sterilized controlled talc was most frequently used for pleurodesis in our cohort, with OK-432 being the second most used material. No severe complications of pleurodesis were observed in the study cohort. Among patients who underwent pleurodesis, the decline in $\mathrm{VC}$ at 6 months in patients who used talc and those who did not use talc were $-12.9 \% \pm 4.2 \%$ and $-22.2 \% \pm 2.8 \%$, respectively $(P=.076)$. The decline in $\mathrm{VC}$ at 12 months in patients who used talc and those who did not use talc were $-13.9 \% \pm 2.6 \%$ and $-17.6 \% \pm 2.0 \%$, respectively $(P=.277)$ (Figure 3, $A)$. The decline in the FEV1 at 6 months in patients who used talc and those who did not use talc were $-12.3 \% \pm 4.3 \%$ and $-15.0 \% \pm 2.8 \%$, respectively $(P=.603)$. The decline of FEV1 at 12 months in patients who did and did not use talc were $-11.9 \% \pm 2.5 \%$ and $-12.4 \% \pm 1.9 \%$, respectively $(P=.890)$ (Figure 3, $B$ ).

\section{DISCUSSION}

The present study found that patients who underwent pleurodesis had significantly reduced postoperative $\mathrm{VC}$ compared with those who did not undergo pleurodesis (Figure 4). In our study, there were no differences in changes in the pulmonary function between patients who had no APF and patients who had APF on POD 2 but did not undergo pleurodesis. However, the decline in $\mathrm{VC}$ was greater in patients who underwent pleurodesis than in those who had APF on POD 2 but did not undergo pleurodesis. These results indicate that even after discounting the effects of APF, pleurodesis exerts a negative impact on pulmonary function. The difference in the decline in $\mathrm{VC}$ in the present study was about $5.5 \%$, and it is unclear whether this degree of decline in pulmonary function could be noticed by patients or recovered via rehabilitation. This decline in pulmonary function is equivalent to 1 segment of 

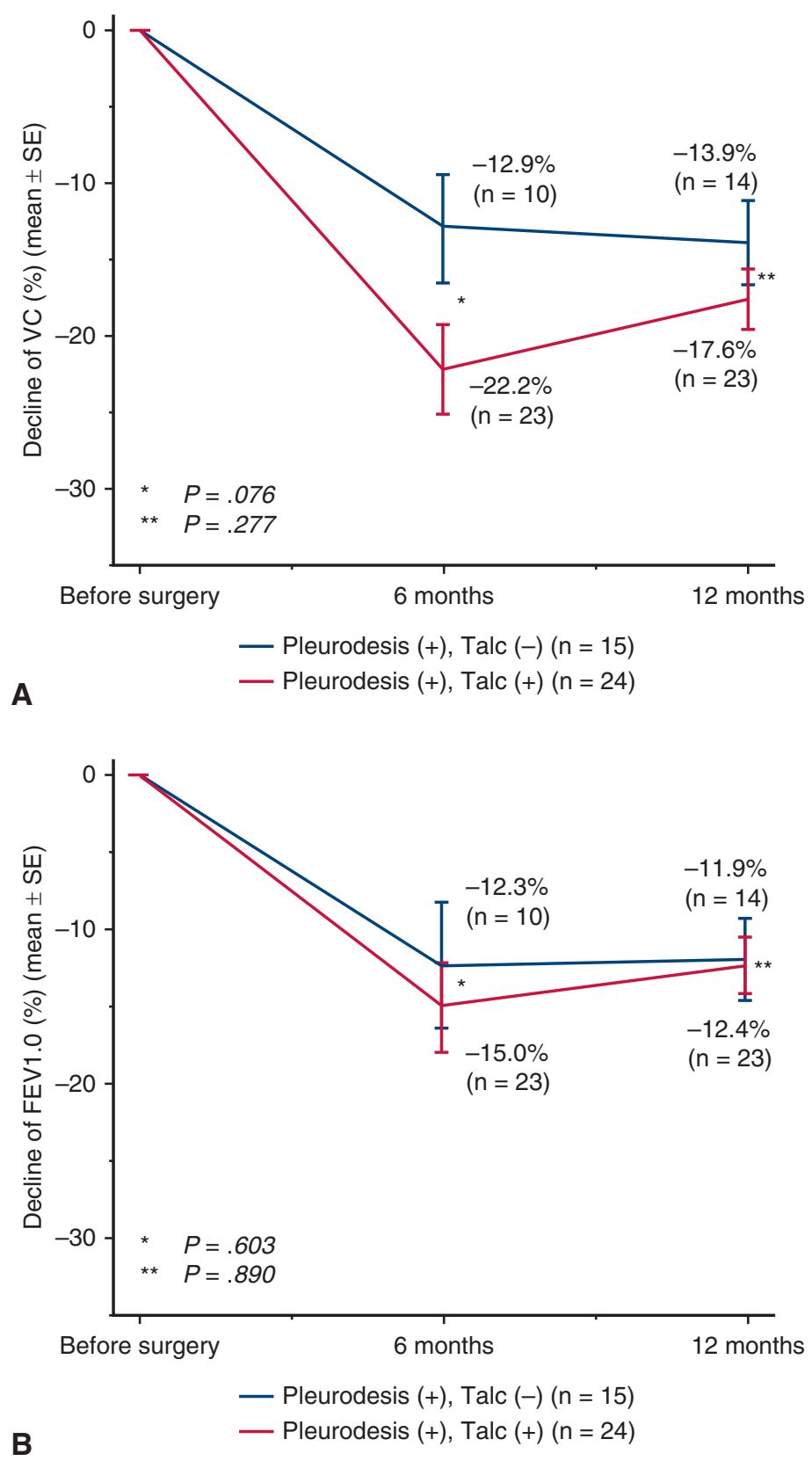

FIGURE 3. A, Difference in the decline in the vital capacity $(V C)$ between patients who used talc and those who did not use talc. Among patients who underwent pleurodesis, the decline in $\mathrm{VC}$ at 6 months postoperatively in patients who used talc and those who did not use talc were $-12.9 \% \pm 4.2 \%$ and $-22.2 \% \pm 2.8 \%$, respectively $(P=.076)$. The decline in $\mathrm{VC}$ at 12 months postoperatively in patients who used talc and those who did not use talc were $-13.9 \% \pm 2.6 \%$ and $-17.6 \% \pm 2.0 \%$, respectively $(P=.277)$. B, Difference in the decline in expiratory volume in 1 second (FEV1.0) between patients who used talc and those who did not use talc. The decline in the FEV1 at 6 months postoperatively in patients who used talc and those who did not use talc were $-12.3 \% \pm 4.3 \%$ and $-15.0 \% \pm 2.8 \%$, respectively $(P=.603)$. The decline in the FEV1.0 at 12 months postoperatively in patients who used talc and those who did not use talc were $-11.9 \% \pm 2.5 \%$ and $-12.4 \% \pm 1.9 \%$, respectively $(P=.890)$. SE, Standard error.

all 18 segmental bronchi ( 1 out of 18 [5.6\%]) and may not be meaningful in segmentectomy for patients with sufficient pulmonary function but may be important in segmentectomy for compromised patients.

Pleurodesis remains among the effective strategies for prolonged air leak ${ }^{7,8}$ and chylothorax ${ }^{13}$; however, several complications and disadvantages for pleurodesis have been reported. ${ }^{14-16}$ For instance, 1 study revealed severe pain or fever after injection of chemical materials. ${ }^{16}$ There are also reports on acute respiratory distress syndrome after talc or OK-432 administration. ${ }^{14,15}$ Moreover, another study showed that pleurodesis could induce acute 


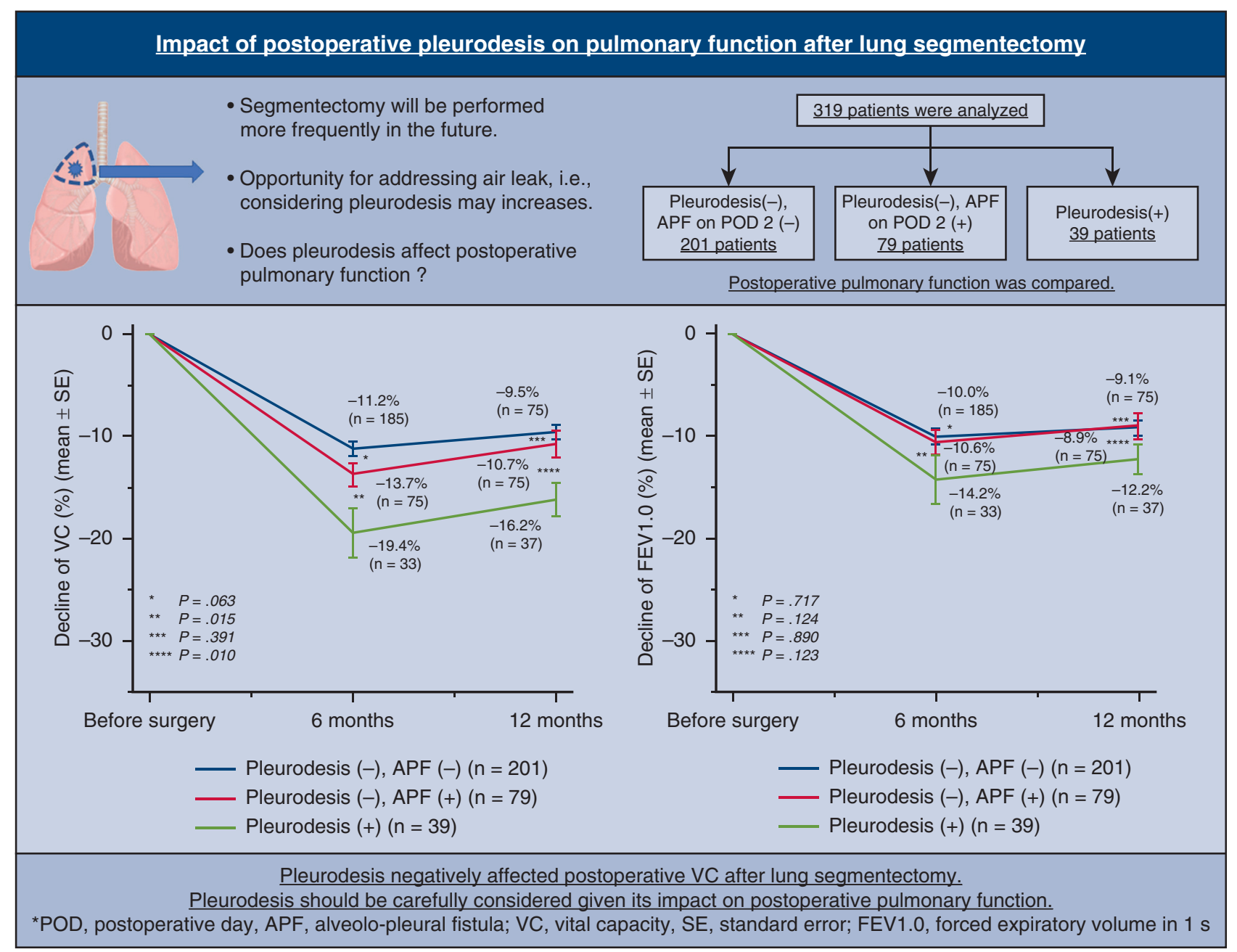

FIGURE 4. Among patients who did not undergo pleurodesis, there were no differences in the decline in vital capacity $(V C)$ at 6 months $(-13.7 \% \pm 1.1 \%$ vs $-11.2 \% \pm 0.7 \% ; P=.063)$ and 12 months $(-10.7 \% \pm 1.3 \%$ vs $-9.5 \% \pm 0.7 \% ; P=.391)$ postoperatively between patients who did and did not have APF on postoperative day (POD) 2. Patients who underwent pleurodesis had a significantly greater decline in VC at 6 months $(-19.4 \% \pm 2.4 \%$ vs $-13.7 \% \pm 1.1 \% ; P=.015)$ and 12 months postoperatively $(-16.2 \% \pm 1.6 \%$ vs $-10.7 \% \pm 1.3 \% ; P=.010)$ than those who had APF and did not undergo pleurodesis. Although there were no significant differences in the decline in expiratory volume in 1 second (FEV1.0), pleurodesis should be carefully considered because it may negatively affect the postoperative pulmonary function. $S E$, Standard error; $A P F$, alveolo-pleural fistula.

exacerbation of $\mathrm{IP}^{17}$ which is why our institution avoids performing pleurodesis as much as possible among those with IP. Pleurodesis using an autologous blood patch had been reported to be safer and result in fewer complications than chemical pleurodesis. ${ }^{18,19}$ In cases of large fistulae, the risk of chemical pneumonia due to aspiration of pleurodesis material through the fistula also can be significant. ${ }^{20}$ Although early treatment for APF is important, the level of evidence supporting pleurodesis has been limited. ${ }^{21}$ In the present study, patients who underwent pleurodesis had been found to have significantly lower pulmonary function than those who did not. The results presented herein suggest that pleurodesis should be carefully performed, especially among patients who are expected to have insufficient postoperative pulmonary function, such as those with severe pulmonary disease.
The mechanism of cessation of air leak by pleurodesis is not well known and may vary depending on the materials used. Adhesion between the visceral and parietal pleura resulting from vigorous inflammatory response in the pleura has been considered to be the main mechanism of air leak cessation. One study reported that visceral pleura thickening is the mechanism whereby pleurodesis by talc stops air leaks. ${ }^{22}$ In any case, the aforementioned mechanisms may inhibit lung expansion and explain why VC was more severely decreased than FEV1. Moreover, although there were no significant differences, it appears that the decline in VC was slightly greater in patients after pleurodesis with talc. Moreover, there is a safety issue in the use of talc for patients with potential long-term survival, particularly with more recent evidence of asbestos contamination. $^{23,24}$ 
Some limitations of the present study are worth noting. First, this was a retrospective study from a single institution with a limited number of included patients. Second, detailed information regarding the amount of air leakage could not be obtained because a 3-bottle drainage system had been used during the early periods of this study, whereas quantitative evaluation was impossible. However, patient characteristics, including preoperative pulmonary function and comorbidities that could affect postoperative APF, had been well balanced between patients who had APF on POD 2 but did not undergo pleurodesis and those who underwent pleurodesis. Therefore, the possible influence of factors other than pleurodesis can be considered minimal. Next, at our institution, there was no strict algorithm for undergoing pleurodesis, and the treatment strategy was left to the discretion of the attending surgeon of each patient based on the quantity of air leak or comorbidity of each patient, such as IP. The surgeons had different preferences; that is, some surgeons performed early pleurodesis expecting early chest tube removal and others avoided pleurodesis as much as possible. Materials used for pleurodesis were also heterogeneous. Accurate comparison groups were difficult to establish. Thus, randomized trials are necessary to accurately assess the influence of pleurodesis. However, it may be challenging because of the differences in indication, procedures, and materials used for pleurodesis among institutions. Despite the above-mentioned limitations of this study, we believe that the present results can help physicians and surgeons decide whether or not pleurodesis is appropriate.

\section{CONCLUSIONS}

The present study showed that among the patients who underwent segmentectomy, those who underwent pleurodesis exhibited a significantly greater decline in VC than those who did not. Pleurodesis negatively influenced the postoperative $\mathrm{VC}$ after lung segmentectomy. Although the clinical influence remains unknown and randomized trials are necessary to confirm the effect, careful consideration is required before performing pleurodesis, given its potential influence on postoperative pulmonary function.

\section{Conflict of Interest Statement}

The authors reported no conflicts of interest.

The Journal policy requires editors and reviewers to disclose conflicts of interest and to decline handling or reviewing manuscripts for which they may have a conflict of interest. The editors and reviewers of this article have no conflicts of interest.

\section{References}

1. Goya T, Asamura H, Yoshimura H, Kato H, Shimokata K, Tsuchiya R, et al. Prognosis of 6644 resected non-small cell lung cancers in Japan: a Japanese lung cancer registry study. Lung Cancer. 2005;50:227-34.
2. Ginsberg RJ, Rubinstein LV. Randomized trial of lobectomy versus limited resection for T1 N0 non-small cell lung cancer. Lung cancer study group. Ann Thorac Surg. 1995;60:615-22.

3. Okada M, Koike T, Higashiyama M, Yamato Y, Kodama K, Tsubota N. Radical sublobar resection for small-sized non-small cell lung cancer: a multicenter study. J Thorac Cardiovasc Surg. 2006;132:769-75.

4. El-Serif A, Gooding WE, Santos R, Pettiford B, Ferson PF, Fernando HC, et al. Outcomes of sublobar resection versus lobectomy for stage I non-small cell lung cancer: a 13-year analysis. Ann Thorac Surg. 2006;82:408-15.

5. Tsutani Y, Miyata Y, Nakayama H, Okumura S, Adachi S, Yoshimura M, et al. Appropriate sublobar resection choice for ground glass opacity-dominant clinical stage IA lung adenocarcinoma: wedge resection or segmentectomy. Chest. 2014;145:66-71.

6. Suzuki K, Saji H, Aokage K, Watanabe S, Okada M, Mizusawa J, et al. Comparison of pulmonary segmentectomy and lobectomy: safety results of a randomized trial. J Thorac Cardiovasc Surg. 2019;158:895-907.

7. Bronstein ME, Koo DC, Weigel TL. Management of air leaks post-surgical lung resection. Ann Transl Med. 2019;15:361.

8. Dugan KC, Laxmanan B, Murgu S, Hogarth DK. Management of persistent air leaks. Chest. 2017;152:417-23.

9. Harada H, Okada M, Sakamoto T, Matsuoka H, Tsubota N. Functional advantage after radical segmentectomy versus lobectomy for lung cancer. Ann Thorac Surg. 2005;80:2041-5.

10. Okada M, Sakamoto T, Yuki T, Mimura T, Miyoshi K, Tsubota N. Hybrid surgical approach of video-assisted minithoracotomy for lung cancer: significance of direct visualization on quality of surgery. Chest. 2005;128:2696-701.

11. Kagimoto A, Tsutani Y, Izaki Y, Handa Y, Mimae T, Miyata Y, et al. Initial experience of robotic anatomical segmentectomy for non-small cell lung cancer. Jpn J Clin Oncol. 2020;50:440-5.

12. Handa Y, Tsutani Y, Mimae T, Tasaki T, Miyata Y, Okada M. Surgical outcomes of complex versus simple segmentectomy for stage I non-small cell lung cancer. Ann Thorac Surg. 2019;107:1032-9.

13. Cho HJ, Kim DK, Lee GD, Sim HJ, Choi SH, Kim HR, et al. Chylothorax complicating pulmonary resection for lung cancer: effective management and pleurodesis. Ann Thorac Surg. 2014;97:408-13.

14. Ogawa K, Takahashi Y, Murase K, Hanada S, Uruga H, Takaya H, et al. OK-432 pleurodesis for the treatment of pneumothorax in patients with interstitial pneumonia. Respir Investig. 2018;56:410-7.

15. Jabłoński S, Kordiak J, Wcisło S, Terlecki A, Misiak P, Santorek-Strumiłło E, et al. Outcome of pleurodesis using different agents in management prolonged air leakage following lung resection. Clin Respir J. 2018;12:183-92.

16. Liberman M, Muzikansky A, Wright CD, Wain JC, Donahue DM, Allanet JS, et al. Incidence and risk factors of persistent air leak after major pulmonary resection and use of chemical pleurodesis. Ann Thorac Surg. 2010;89:891-8.

17. Shinno Y, Kage H, Chino H, Inaba A, Arakawa S, Noguchi S, et al. Old age and underlying interstitial abnormalities are risk factors for development of ARDS after pleurodesis using limited amount of large particle size talc. Respirology. 2018;23:55-9.

18. Chambers A, Routledge T, Bille A, Scarci M. Is blood pleurodesis effective for determining the cessation of persistent air leak? Interact Cardiovasc Thorac Surg. 2010;11:468-72.

19. Manley K, Coonar A, Wells F, Scarci M. Blood patch for persistent air leak: a review of the current literature. Curr Opin Pulm Med. 2012;18:333-8.

20. Li CY, Kuo SW, Lee JM. Life-threatening complications related to minocycline pleurodesis. Ann Thorac Surg. 2011;92:1122-4.

21. Singhal S, Ferraris VA, Bridges CR, Clough ER, Mitchell JD, Fernando HC, et al. Management of alveolar air leaks after pulmonary resection. Ann Thorac Surg. 2010;89:1327-35.

22. Muta F, Takamori S, Matsuo T, Iwasaki Y, Yoshiyama K, Shirouzu K. Changes in the pleural cavity by pleurodesis using talc or OK-432: an experimental study. Surg Today. 2011;41:111-4.

23. Ghio AJ, Roggli V, Light RW. Talc should not be used for pleurodesis in patients with nonmalignant pleural effusions. Am J Respir Crit Care Med. 2001;164: 1741.

24. Baiu I, Yevudza E, Shrager JB. Talc pleurodesis: a medical, medicolegal, and socioeconomic review. Ann Thorac Surg. 2020;109:1294-301.

Key Words: pleurodesis, segmentectomy, pulmonary function 